\title{
Physical activity programs for older people in the community receiving home care services: systematic review and meta-analysis
}

This article was published in the following Dove Press journal:

Clinical Interventions in Aging

Elissa Burton '
Kaela Farrier
Rose Galvin ${ }^{2}$
Shanthi Johnson ${ }^{3}$
N Frances Horgan
Austin Warters
Keith D Hill'
'School of Physiotherapy and Exercise
Science, Curtin University, Perth,
Western Australia, Australia; ${ }^{2}$ School of
Allied Health, Faculty of Education and
Health Sciences, Health Research
Institute, University of Limerick,
Limerick, Ireland; ${ }^{3}$ School of Public
Health, University of Alberta, Edmonton,
AB, Canada; ${ }^{4}$ School of Physiotherapy,
Royal College of Surgeons in Ireland,
Dublin, Ireland; ${ }^{5}$ Health Service
Executive, Dublin North City and County
Healthcare Organisation, Dublin, Ireland

Correspondence: Elissa Burton School of Physiotherapy and Exercise Science, Curtin University, GPO Box UI987, Perth, Western Australia 6845, Australia

Tel +6 I892664926

Fax +6 I89266 3699

Email E.Burton@curtin.edu.au

\begin{abstract}
The proportion of older adults is increasing around the world and most wish to live in their home until they die. To achieve this, many will require services in the home to remain living independently. To maintain function (ie, strength, balance, and endurance), physical activity needs to be undertaken on a regular basis, and is essential as a person ages. Unfortunately, as people age there is a tendency to reduce activity levels, which often leads to loss of function and frailty, and the need for home care services. This updated systematic review includes a mix of study methodologies and meta-analysis, and investigated the effectiveness of physical activity/exercise interventions for older adults receiving home care services. Eighteen studies including ten randomized controlled trials meeting the selection criteria were identified. Many of the studies were multi-factorial interventions with the majority reporting aims beyond solely trying to improve the physical function of home care clients. The meta-analysis showed limited evidence for effectiveness of physical activity for older adults receiving home care services. Future exercise/physical activity studies working with home care populations should consider focusing solely on physical improvements, and need to include a process evaluation of the intervention to gain a better understanding of the association between adherence to the exercise program and other factors influencing effectiveness.
\end{abstract}

Keywords: exercise, physical function, community care, reablement, seniors

\section{Introduction}

Populations throughout the world are increasing in age, with greater proportions of older people than previously observed. ${ }^{1}$ Most older people have a desire to live in their home until they die ${ }^{2}$ and to do this, they need to be able to complete activities of daily living (ADLs) such as showering, dressing, eating, and toileting independently. For some older adults these tasks become increasingly difficult due to health issues, frailty or disability, and they require assistance to continue living in their home. ${ }^{3}$ This assistance is often provided by home or community care services and is predominantly funded by the government in high income countries such as Australia, Canada, and a number of European countries. ${ }^{4-6}$

Home care services can be delivered over the short or longer term. ${ }^{7}$ Some shortterm reablement services (ie, goal-oriented, person-centered, often aimed at reduced long-term services) include physical activity or exercise programs, whereas the longer term services such as personal care (ie, showering), domestic assistance (ie, cleaning), gardening, transport, and social support usually do not. In order to assist 
an older person to continue living in their home and complete their ADLs, they need to maintain strength, balance, and endurance. ${ }^{8,9}$

Improving or maintaining strength, balance, and endurance requires a desire to be active, the knowledge of what to do, and the opportunity to be active. ${ }^{10,11}$ The World Health Organization and many individual countries (ie, United States, Canada, Great Britain, Australia) have produced National Physical Activity Guidelines for older adults. $^{12-15}$ They predominantly recommend 30 minutes of moderate intensity endurance physical activity every day such as walking or swimming, in addition to strength and balance training twice a week. ${ }^{12-15}$ The strength and balance components are essential for maintaining independence and completing ADLs. ${ }^{16}$ Strength and balance training also leads to many health benefits such as increased strength and bone density, reduction in sarcopenia, frailty, and chronic illness ${ }^{9,16-18}$ and has the strongest evidence for preventing falls for older adults living in the community. ${ }^{19}$ Unfortunately, these exercise modalities are often overlooked when promoting physical activity recommendations to older adults, particularly those receiving home care services. ${ }^{20}$

Many older home care clients walk to be active, however few participate in strength and balance programs. ${ }^{21}$ It can be difficult for home care clients to leave their home, and typically, shopping and medical appointments are prioritized, particularly when assistance with transport is required. To support older adults receiving home care services to, at a minimum, maintain their strength and balance, and at best, improve it over time, promoting physical activity within the home is required. Organizations delivering home care services have the ideal opportunity to do this, as many home care workers deliver services from once a week to multiple times each week. A previous systematic review ${ }^{22}$ evaluated the effectiveness of physical activity (exercise) programs for home care clients, however, at the time only eight articles were identified. The evidence (ie, outcomes and assessments) varied widely and was limited, as such, a meta-analysis could not be undertaken. Therefore, as the focus on older adults receiving home care services continues to increase, it is essential to identify whether further studies have been undertaken. This will help guide home and community care organizations to provide evidence-based care for their older clients and assist policy-makers to understand the benefits of improved physical function for this older population whom they heavily fund (eg, Irish government spends $€ 408$ million on home support each year which equates to 17 million visits). ${ }^{6}$ This current systematic review looks at the recent evidence and where possible combines the randomized controlled trials (RCTs) $(n=2)$ from the previous systematic review with more recently published studies, to determine the effectiveness of physical activity/exercise programs delivered specifically to older adults receiving home care services.

\section{Material and methods Eligibility criteria}

The review is limited to studies that met the following eligibility criteria:

- population: aged 65 years and older (at least $50 \%$ of sample) and receiving home care services during the intervention. Home care services may include (but not limited to) personal care (showering), domestic assistance, transport, shopping or social care. These services are delivered in an older persons home by home or community care organizations (ie, municipalities etc) and can be short-term or long-term ongoing services.

- Intervention: has to have a physical activity or exercise aspect to the intervention.

- Comparison: for RCTs the comparison group will be usual care (ie, which may include a current physical activity or exercise program used) or a non-active control group.

- Outcomes: the physical activity or exercise intervention has to have been assessed using at least one physical performance outcome (ie, mobility, endurance, strength, balance).

- Setting: community-dwelling people only.

Any quantitative study could be included, eg, pilot or feasibility, pre- and post-test, retrospective, controlled trials or RCTs. Only peer-reviewed journal articles in English were included. No unpublished data (ie, reports), books, conference proceedings, theses, or poster abstracts were included. Exclusion criteria were: those living in residential care, and samples with $>50 \%$ with a diagnosis of dementia or neurodegenerative disorder because they often require greater supervision and/or carer input to complete the physical activity/exercise intervention and therefore may not be representative of a typical home care service. 


\section{Information sources}

Five databases were searched between October 2012 and August 2018: Medline (Proquest); CINAHL; PubMed; PsycInfo; and SportDiscus. The previous systematic review search included articles between January 1982 to September 2012. Reference lists from these papers were also scanned.

\section{Search strategy}

The search included the same mix of keywords as used in the previous systematic review. However, this updated review also included "reablement" as a search term. An example of the search strategy is presented in Table 1.

\section{Study selection}

Study selection was conducted in three stages. Stage one was the initial screening of the titles and scanning the abstracts against the eligibility criteria to identify potential articles (completed by KF). Stage two included screening the full articles by two authors (EB and KF) to identify whether they met the eligibility criteria. In stage three, disagreements were resolved through discussion between $\mathrm{EB}$ and $\mathrm{KF}$ to achieve consensus, after referring to the eligibility criteria and protocol. The PRISMA checklist was used to ensure the results were reported systematically. ${ }^{23}$

\section{Table I Search strategy}

\begin{tabular}{|l|l|}
\hline 1 & Community care \\
2 & Community health care \\
4 & Home care \\
5 & Community nursing \\
6 & Home and community care \\
7 & Home support \\
8 & Community rehabilitations \\
9 & Restorative care \\
10 & Reablement \\
11 & I or 2 or 3 or 4 or 5 or 6 or 7 or 8 or 9 \\
12 & Physical activity \\
13 & Exercis* \\
14 & II or 12 \\
15 & Ageing \\
16 & Aging \\
17 & Aged \\
18 & Older \\
19 & Elderly \\
20 & 14 or 15 or 16 or 17 or 18 \\
\hline
\end{tabular}

\section{Data collection process}

Each study in the review was evaluated using a standardized extraction form, which included study design; purpose; intervention; study characteristics including sample size, sex proportion, participant age, intervention type; and length of follow-up (Tables 2 and 3).

\section{Study quality}

Study quality for the RCTs was assessed by two independent researchers (KF and $\mathrm{RG}$ ) using the Cochrane's Risk of Bias Tool. ${ }^{24}$ Categories assessed by the tool include sequence generation, allocation concealment, blinding of participants, blinding of outcome assessment, incomplete outcome data, selective outcome reporting, and other sources of bias. ${ }^{24}$ RCT studies were assessed as having "low", "medium" or "high" risk of bias. Discussions were undertaken between the reviewers and where required, a third researcher (EB), to form consensus.

Study quality was reviewed by two researchers (KF, EB) for all other included papers, using the National Institute for Health and Care Excellence (NICE) guidelines appraisal checklist. ${ }^{25}$ The internal and external validity of the included papers were assessed by addressing key aspects of study design such as participant characteristics, allocation and intervention details, outcomes assessed, and methods of analyses. ${ }^{25}$ Each study was awarded an overall study quality grading (ie, ++ all or most of the checklist criteria have been satisfied, where they have not, it was deemed unlikely to alter the conclusions; + some of the checklist criteria have been satisfied, where they have not, it is unlikely these will alter the conclusions; and - few or no checklist criteria have been satisfied and are likely or very likely to alter the conclusions). ${ }^{25}$

\section{Data analysis}

Physical performance outcome measures from the RCTs included in this current review and the previous review ${ }^{22}$ were collated to determine whether there were two or more studies that utilized the same outcome measures. ${ }^{26}$ For those studies that did, a meta-analysis was undertaken. Authors were contacted if data were not available within the published article. Four performance outcomes were utilized in the meta-analyses and all were measured using continuous data: Timed Up and Go (TUG), sit-tostand five times, grip strength, and walking speed. The mean difference (MD) and 95\% CIs were calculated. Review Manager (RevMan) version 5.3 was used to conduct the analyses and generate forest plots with a random 


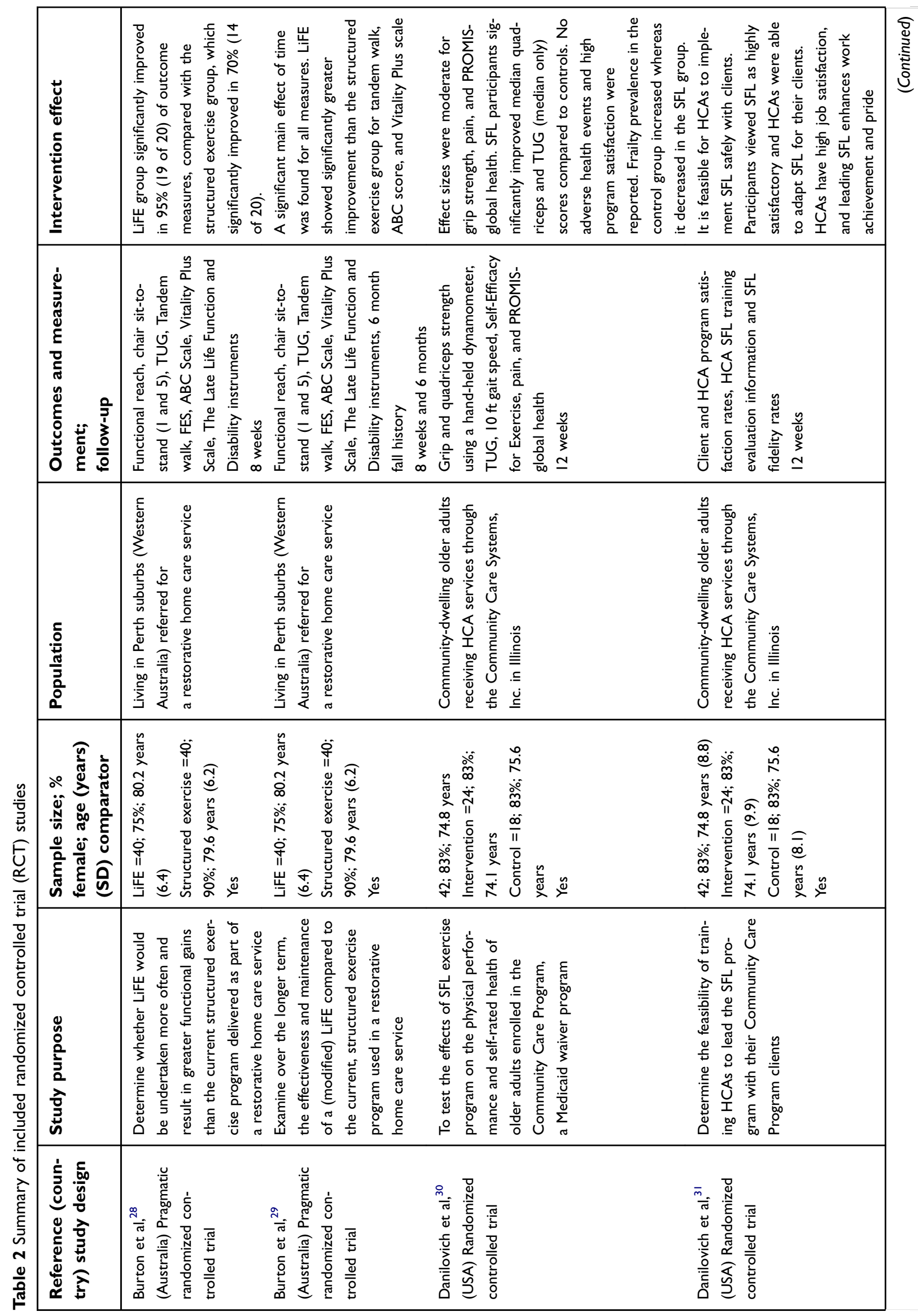




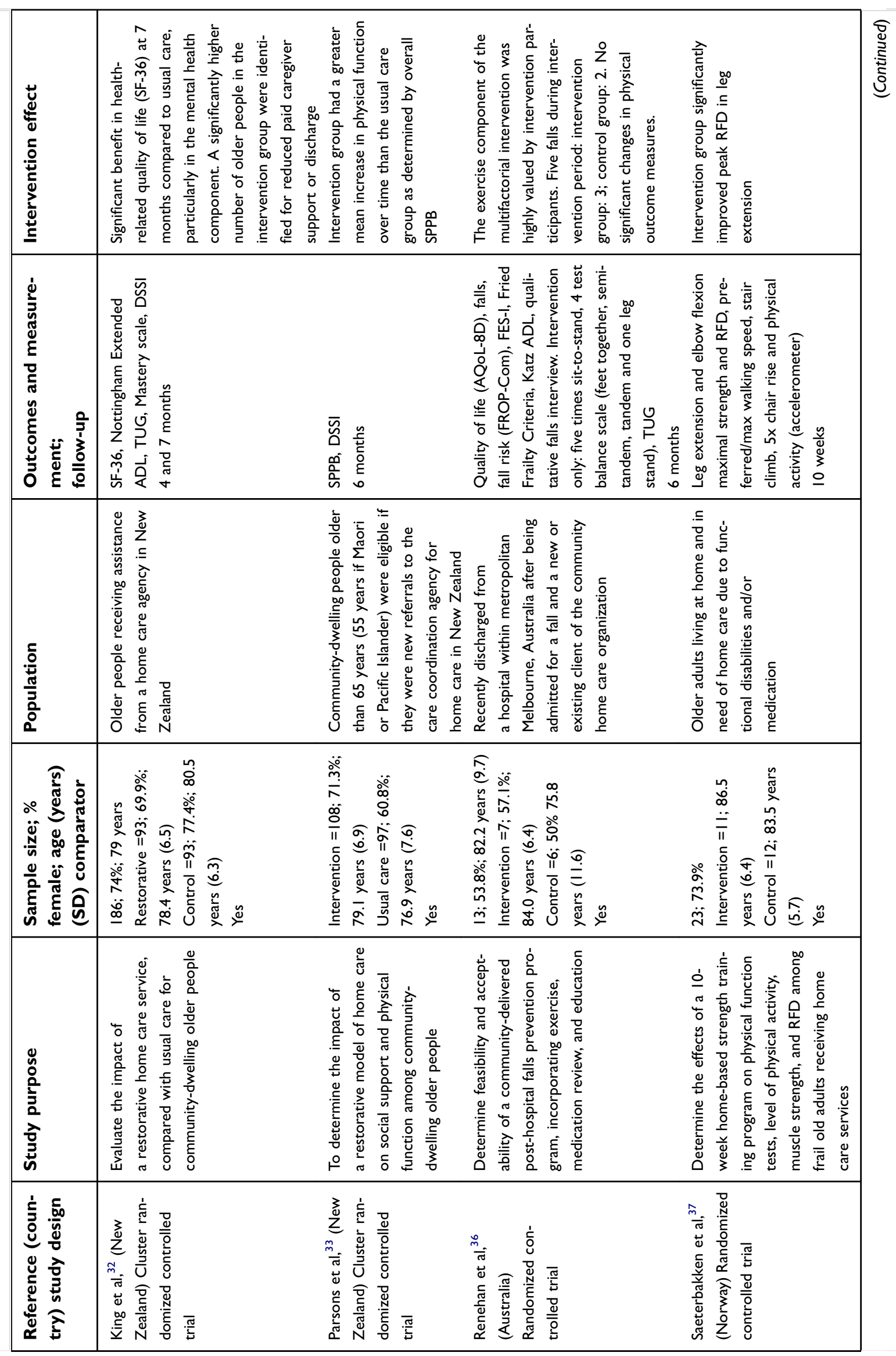




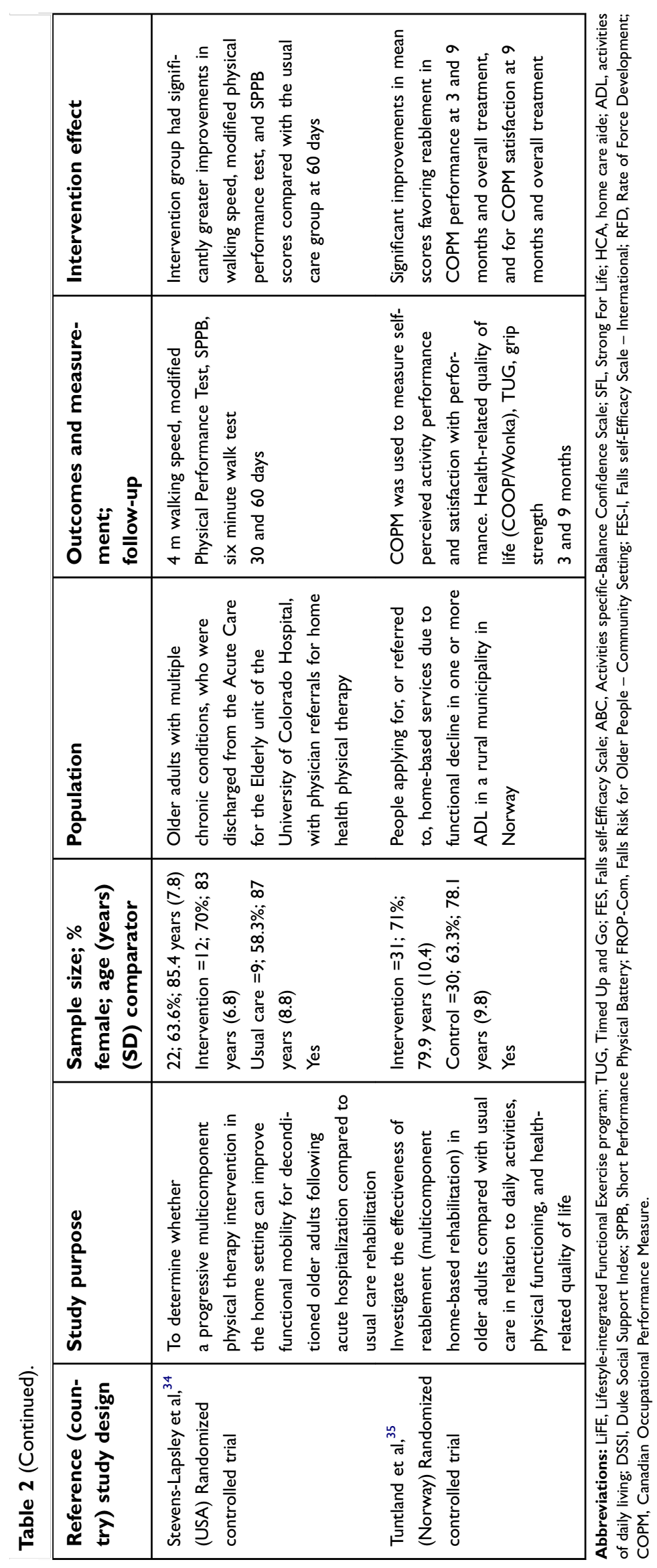




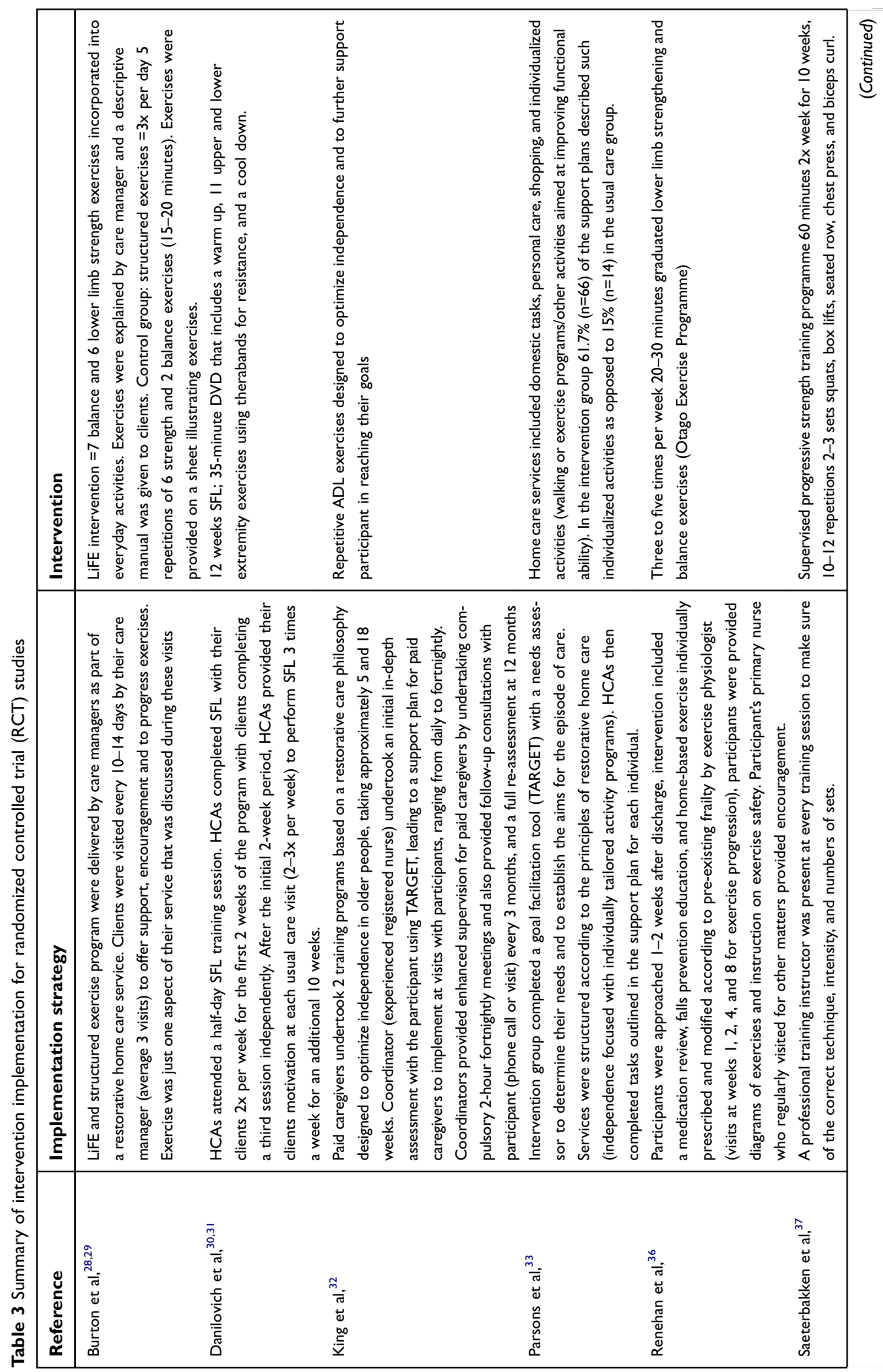




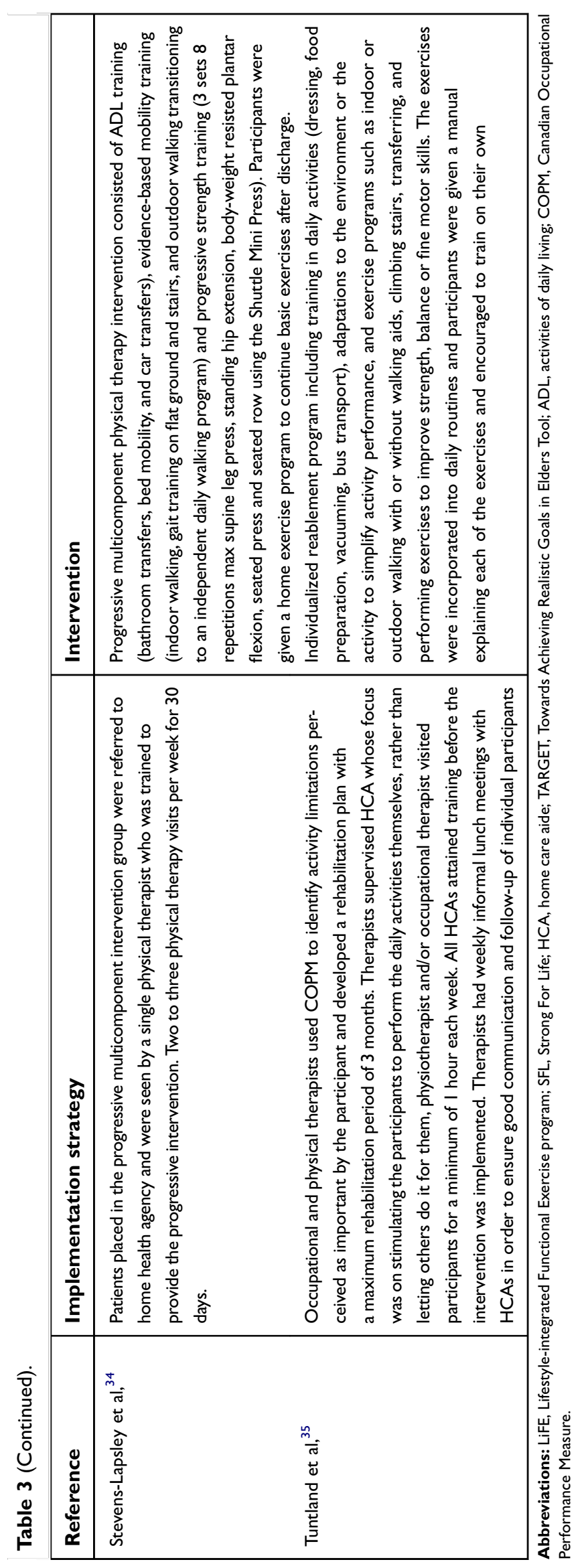


effects model applied and using the inverse variance DerSimonian and Laird method. ${ }^{27}$ Heterogeneity was assessed using the $I^{2}$ statistic and by visual inspection of the forest plots. Statistical significance was set at $p<0.05$ for all analyses.

\section{Results}

\section{Study selection}

Eight thousand seven hundred and fifty eight papers were found in the five databases. After removing duplicates from each database and then across databases, 1,679 articles remained. Articles were screened by title and 1,266 were excluded. Reasons for exclusion are presented in Figure 1 the study flow chart. Article abstracts were then read and a further 288 excluded, leaving 125 articles to be screened by full text. One hundred and seven studies were excluded and 18 studies were accepted to be included in the review.

\section{Study characteristics}

The 18 studies in the review included ten RCTs; ${ }^{28-37}$ six single group pre- and post-test studies; ${ }^{38-43}$ one feasibility study; ${ }^{44}$ and one retrospective study. ${ }^{45}$

There were 1,118 participants across the 18 studies, ranging from eight in a pilot study ${ }^{39}$ to 228 in the retrospective study. ${ }^{45}$ The average age of all participants was $80.4( \pm 3.3)$ years and ranged from $74.5-85.4$ years; $71.8 \%$ of the participants were female. Seven studies were conducted in the United States; ${ }^{30,31,34,38,41,42,45}$ six in Australia; ${ }^{28,29,36,39,43,44}$ two in New Zealand ${ }^{32,33}$ and Norway; ${ }^{35,37}$ and one in Hong Kong. ${ }^{40}$

\section{Interventions \\ RCTs}

The average age of the 656 participants in the ten RCTs was $80.4( \pm 3.7)$ years, ranging from $74.5-85.4$ years and included an average of $69.6 \%$ females. A number of different interventions were trialed. However, the majority focused on strength and balance training. Table 2 presents a summary of the included RCT studies and Table 3 outlines the interventions implemented.

The two Burton et al ${ }^{28,29}$ RCTs utilized the Lifestyleintegrated Functional Exercise (LiFE) program which incorporates seven balance and seven strength exercises into an older person's daily living activities. ${ }^{46,47}$ The intervention was compared with a structured exercise program that focused on strength and balance also in an RCT over two time periods; 8 -week intervention ${ }^{28}$ and a 4-month maintenance period. ${ }^{29}$ It must be noted the control group was active and received the structured exercise program that was delivered within the usual restorative care service. Whereas, Danilovich et al created the Strong For Life (SFL) resistance training program, which included a 35-minute DVD to assist home care aides to deliver the program. ${ }^{30,31}$

The exercise intervention in King et al's study ${ }^{32}$ used exercises that optimized independence, incorporating repetitive functional ADLs. Parsons et $\mathrm{al}^{33}$ used a similar exercise intervention, again with the aim of optimizing independence and improving functional ability by incorporating individualized activities, $62 \%$ of the support plans described included these activities with their participants compared to $15 \%$ for the control group (ie, usual care).

Stevens-Lapsley et al $^{34}$ utilized a progressive multicomponent physical therapy intervention for 60 days to improve functional mobility for older adults who had just left hospital. Tuntland et $\mathrm{al}^{35}$ trialed a reablement intervention, which was individualized for each participant. The exercise programs typically included indoor or outdoor walking, climbing stairs, transferring, engaging in strength and balance training, and improving fine motor skills. Similar to the LiFE program utilized by Burton et $a{ }^{28},{ }^{28}$ many of the exercises were incorporated into ADLs. In a further study by Saeterbakken et al, ${ }^{37}$ they conducted a 10 -week fullysupervised strength training intervention which was delivered twice a week to participants.

\section{Other studies}

The other eight studies that were not RCTs included 462 participants, with an average age of $80.5( \pm 3.0)$ ranging from 76.8-83.8 years and included an average of $74.8 \%$ females. Table 4 presents a summary of the included studies that are not RCTs and Table 5 the interventions implemented. Bamgbase and Dearmon ${ }^{38}$ reported delivering a 6-month individualized home exercise program with no other detail, and the main aim was preventing falls by using a multi-factorial intervention.

Burton et $\mathrm{al}^{39}$ conducted a feasibility study utilizing the LiFE program (previously described) to determine whether this intervention type could be delivered more broadly within a restorative care service. In a more recent study, Burton et $\mathrm{al}^{44}$ conducted a feasibility study that explored whether community care support workers who are nonallied health trained could deliver the LiFE exercise program to community care clients. It was determined that there were no adverse events and it was possible for this population to deliver this falls prevention exercise program. ${ }^{44}$ 


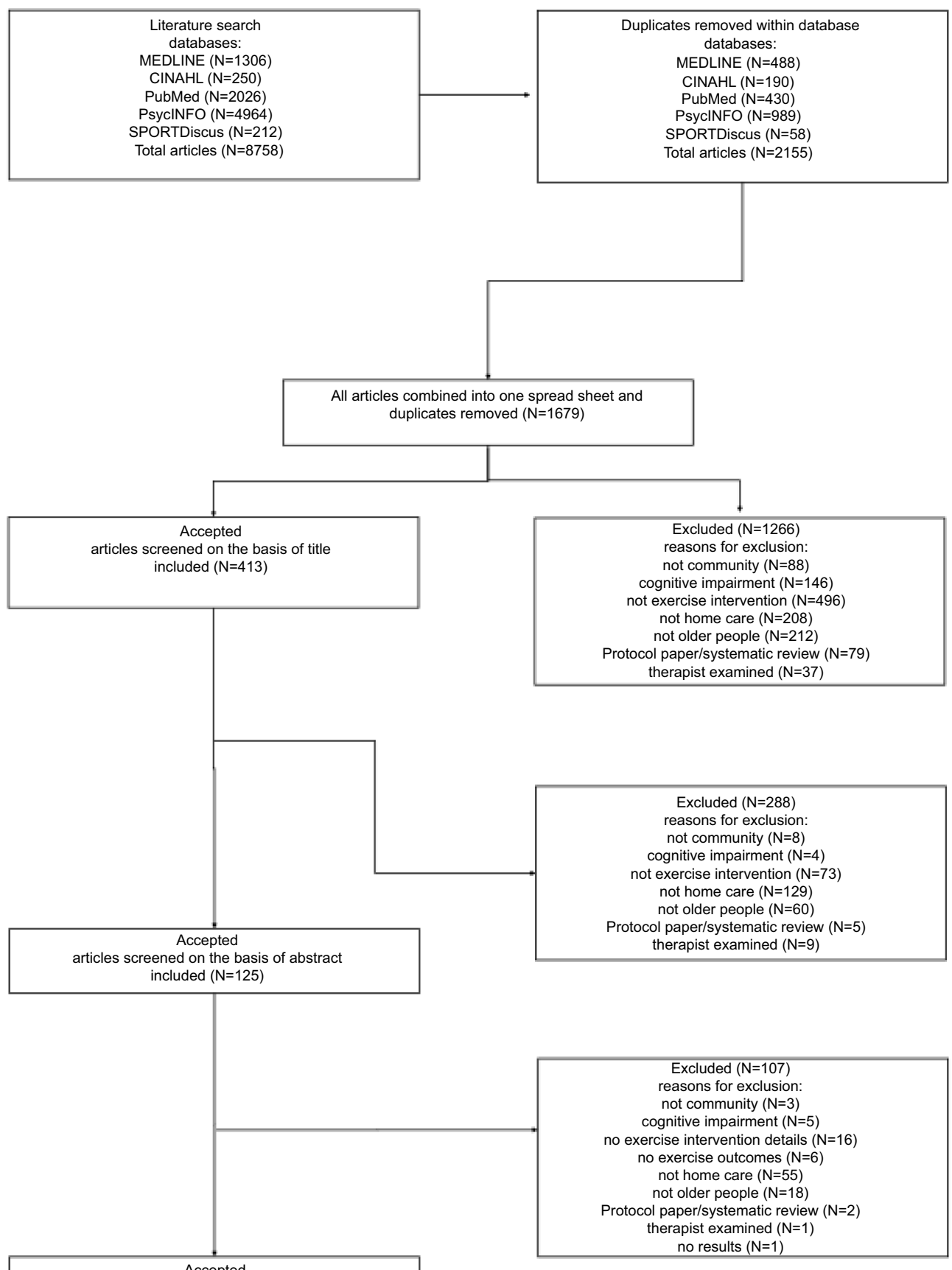

articles screened on the basis of ful text $(\mathrm{N}=18)$

Figure I Flow chart of study selection.

The home care clients in Gallagher et al's study ${ }^{45}$ received an individualized home exercise program which was designed to address clients' identified impairments and falls hazards in the home. This study found that the Missouri Alliance for Home Care tool (MAHC-10) and interdisciplinary program was effective in identifying and managing those who had fallen in their home. ${ }^{45}$

The 6-month intervention delivered by Kwok and Tong $^{40}$ was a multicomponent exercise program, consisting of flexibility, strength, balance, and aerobic exercises, either delivered by a physiotherapist in a center or by a care worker in the home. The physiotherapy-led center-based intervention was found to improve physical function, quality of life, and fall incidence, whereas the home-based care worker led program had no effect on physical function and self-rated health. ${ }^{40}$

Muramatsu et $\mathrm{al}^{41}$ conducted a motivational enhancement and three chair-bound movements program delivered 


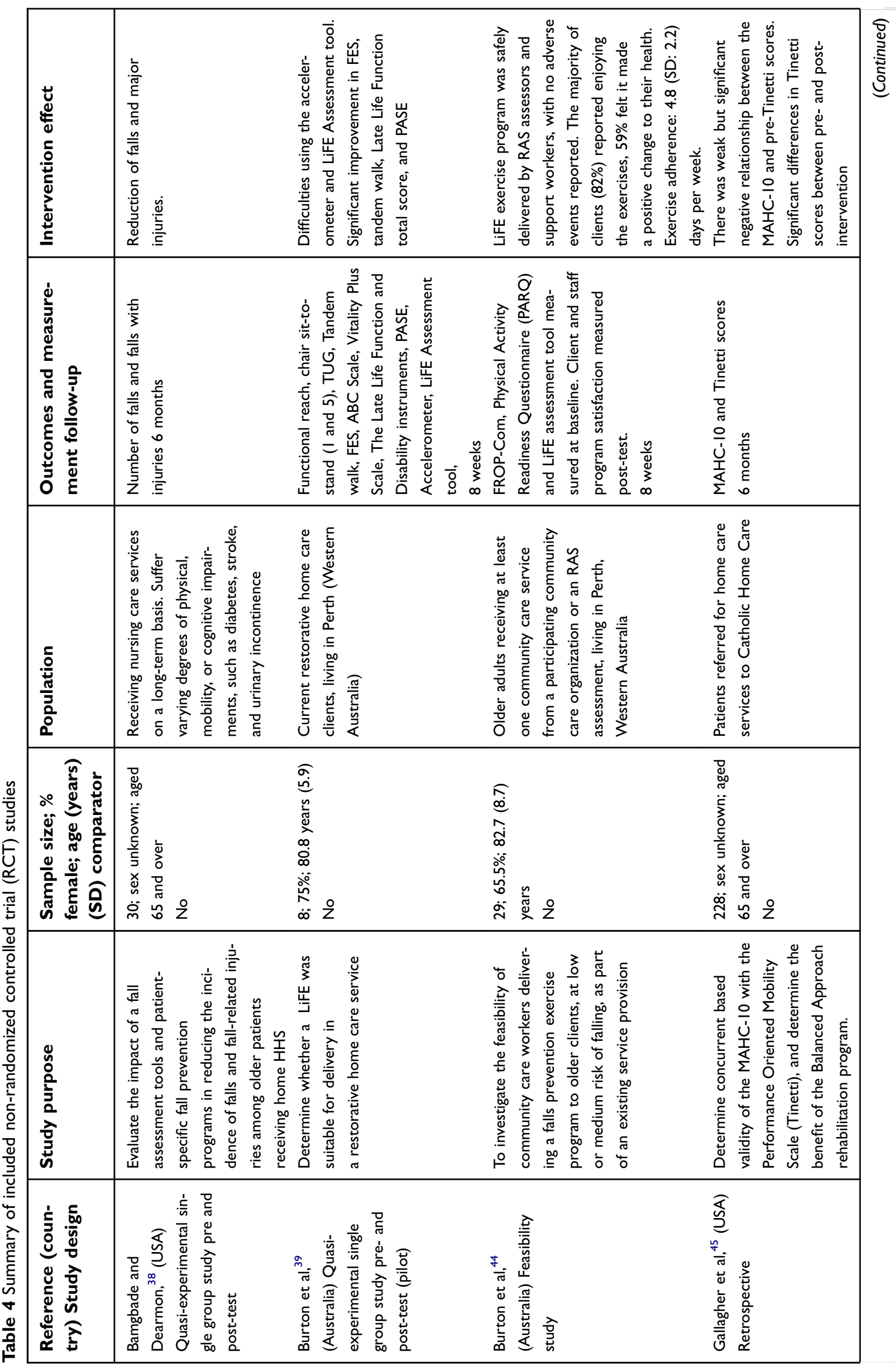




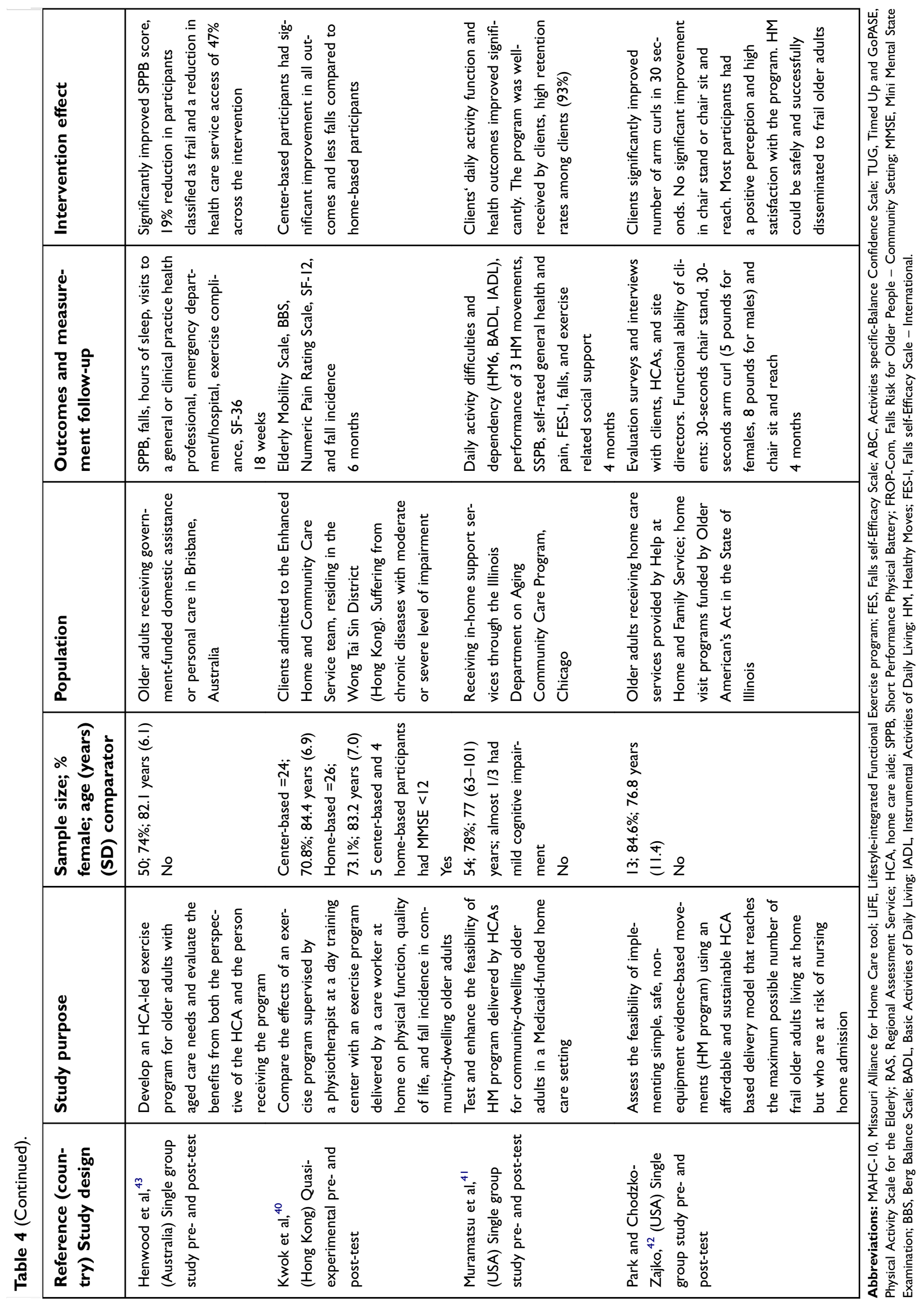




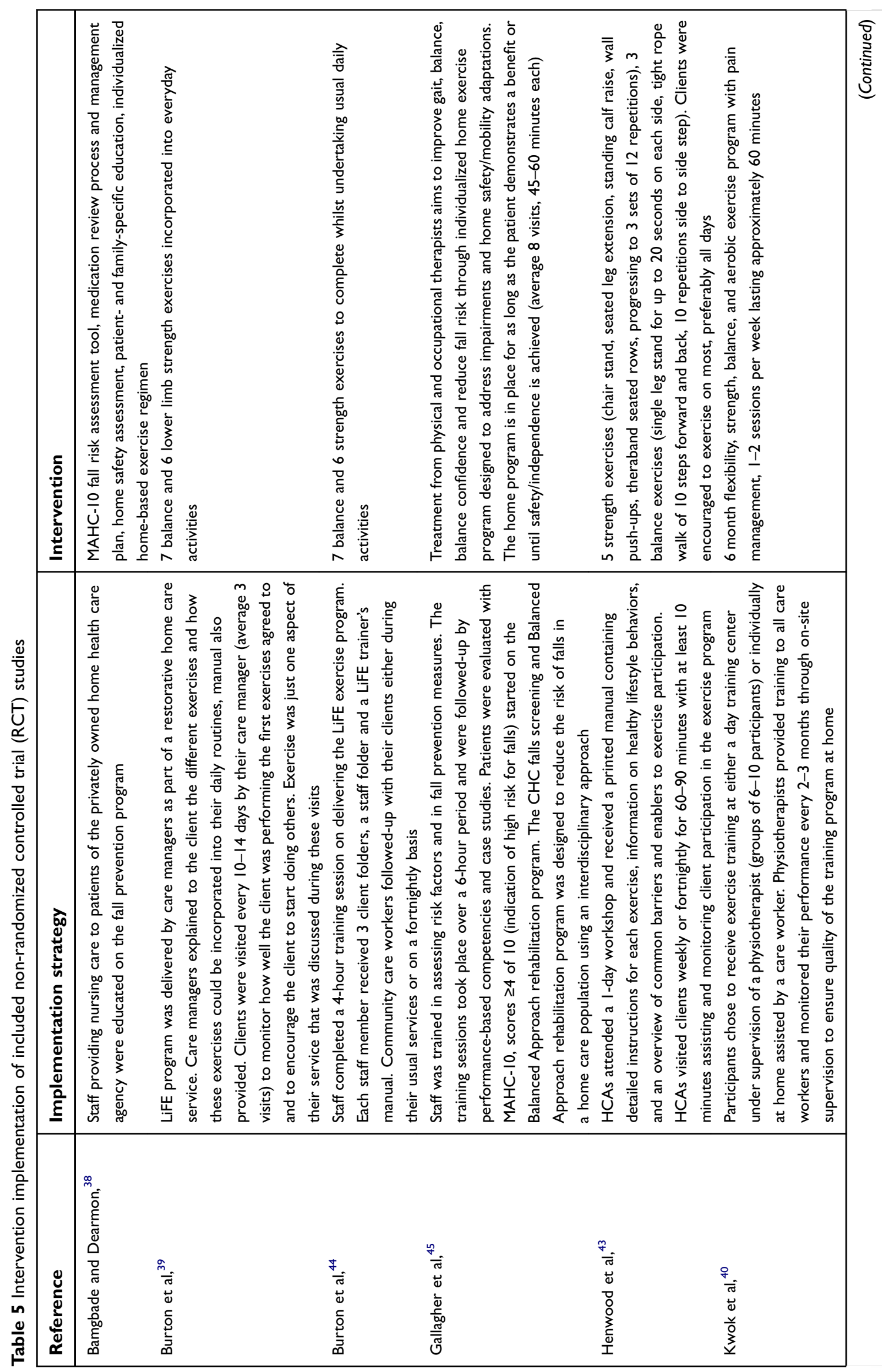




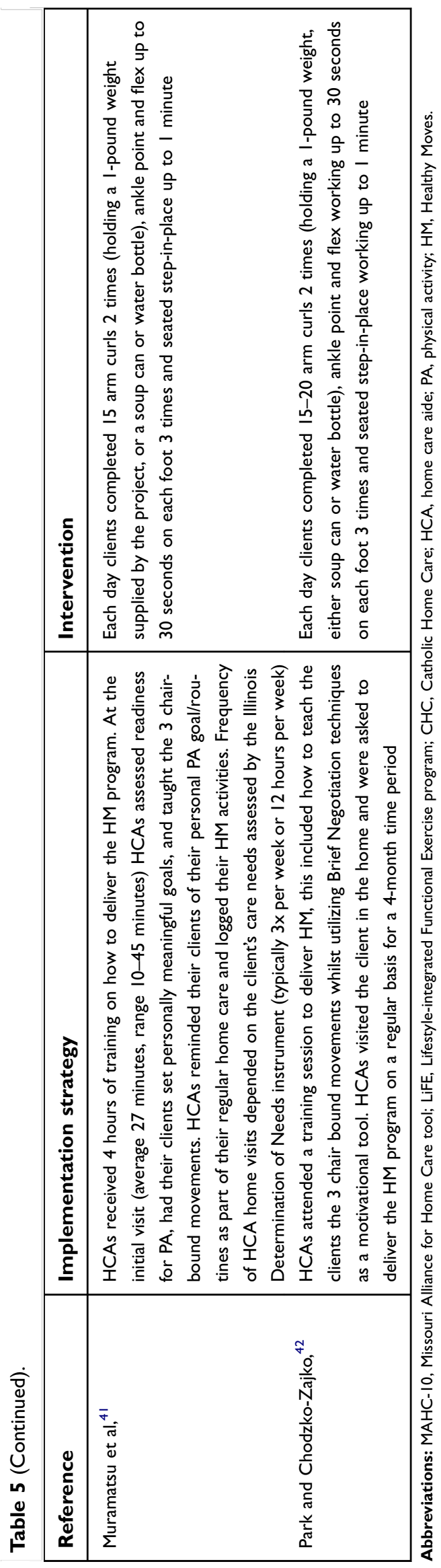

by home care aides for their clients over a 4-month intervention. Results showed a significant improvement in physical fitness, self-rated health, pain interference, Short Physical Performance Battery (SPPB) total score, SPPB balance tests, and fear of falling. ${ }^{41}$ Park and Chodzko-Zajko ${ }^{42}$ also conducted a 4-month intervention called "Healthy moves for aging well" which incorporated a physical activity intervention with a lifestyle behavior change counseling method called Brief Negotiation. The activity portion of the intervention was the same as that used by Muramatsu et al. ${ }^{41}$ Arm curl was the only functional ability outcome that reported improvement between pre- and post-testing $(p=0.021){ }^{42}$

Henwood et al's ${ }^{43}$ Active@Home 18-week program included weight bearing and balance exercises and was tailored to the level of the participant. The exercise program was delivered by home care support workers, with at least 10 minutes of their service time spent monitoring the exercises. ${ }^{43}$ Significant improvement was found for functional capacity as measured by the SPPB and a $19 \%$ reduction in participants classified as frail. ${ }^{43}$

\section{Outcome measures RCTs}

There was a variety of outcome measures utilized by the included studies. The main physical test utilized by five of the RCTs was the TUG test. ${ }^{28-30,32,35}$ Unfortunately Danilovich et $\mathrm{al}^{30}$ could only provide medians and interquartile ranges rather than means and SDs for the TUG, and only the intervention phase data of Burton et al's ${ }^{28}$ study were included to provide similarity with the other studies included which assessed the post-intervention period. Four of the RCTs ${ }^{28,33,37,48}$ used the sit-to-stand five times test and these data have been included in a metaanalysis.

Two RCTs ${ }^{33,34}$ utilized SPPB but unfortunately, after many emails, the authors were unable to obtain the data required for the Stevens-Lapsley et $\mathrm{al}^{34}$ study. Therefore, no meta-analysis could be conducted. The grip strength test $\mathrm{t}^{30,35}$ and gait speed/walking tests were used in two RCTs each respectively. ${ }^{30,34}$ The data from the StevensLapsley et $\mathrm{al}^{34}$ study were not available, however, Tinetti et al's study which was included in the previous systematic review, measured walking speeds and was included in the meta-analysis.

\section{Other studies}

The SPPB test was used in two of the non-RCT studies ${ }^{38,43}$ and five of these studies also collected data on 
Table 6 Randomized controlled trial (RCT) - assessment of risk of bias of RCTs

\begin{tabular}{|c|c|c|c|c|c|c|}
\hline Study & $\begin{array}{l}\text { Sequence } \\
\text { generation }\end{array}$ & $\begin{array}{l}\text { Allocation } \\
\text { concealment }\end{array}$ & Blinding & $\begin{array}{l}\text { Incomplete } \\
\text { outcome data }\end{array}$ & $\begin{array}{l}\text { Selective out- } \\
\text { come reporting }\end{array}$ & $\begin{array}{l}\text { Free of } \\
\text { other bias }\end{array}$ \\
\hline Burton et al, ${ }^{28}$ & + & + & - & + & + & $?$ \\
\hline Burton et al, ${ }^{29}$ & + & + & - & + & + & $?$ \\
\hline Danilovich et al, ${ }^{30}$ & + & $?$ & + & + & $?$ & - \\
\hline Danilovich et al, ${ }^{31}$ & + & $?$ & + & + & $?$ & - \\
\hline King et $\mathrm{al}^{32}$ & + & $?$ & + & + & + & $?$ \\
\hline Parsons et $\mathrm{al}^{33}$ & $?$ & $?$ & + & + & + & - \\
\hline Stevens-Lapsley et al, ${ }^{34}$ & + & $?$ & + & + & + & - \\
\hline Tuntland et al, ${ }^{35}$ & + & + & $?$ & + & + & - \\
\hline Saeterbakken et al, ${ }^{37}$ & + & + & - & - & $?$ & - \\
\hline Renehan et al, ${ }^{36}$ & + & + & + & + & - & - \\
\hline
\end{tabular}

falls, ${ }^{38,40,41,43,45}$ as did Renehan et $\mathrm{al}^{36}$ in their RCT. Other physical performance measures used by single studies included functional reach, sit-to-stand one time, tandem walk (including tandem walk errors), and the six minute walk test. Health-related quality of life was measured using the SF-36, SF-12, EQ5D, AQol-8D, and the COOP/Wonka. Falls related assessments included the falls efficacy scale, activity-specific balance scale, the Falls Risk for the Older Person living in the Community and the MAHC-10 falls assessment tool.

\section{Dropout and adherence to exercise interventions}

Participant withdrawal rates ranged from $3.9 \%{ }^{33} 23.3 \%,{ }^{37}$ with an average dropout rate of $13.5 \%( \pm 7.0)$. Adherence rates were reported in seven of the studies. ${ }^{28,29,37,38,41,43,44}$ Bamgbade and Dearmon ${ }^{38}$ stated $17 \%(n=5)$ of their participants performed the exercises as instructed over the 2 months. In Burton et al's ${ }^{28,29}$ RCT studies, the intervention group reported completing the activities 4.9 times/week during the intervention period ( 8 weeks) and 4.1 times/ week across the 6-month study, and the control group 4.4 times/week during the intervention ( 8 weeks) and 3.7 times/ week across the 6 months. In the 8 -week study, adherence to exercise interventions delivered by community care support workers was reported at $4.9( \pm 2.2)$ times per week. ${ }^{44}$ Henwood et $\mathrm{al}^{43}$ reported adherence of $5.1( \pm 0.6)$ sessions per week across the 18-week intervention and Saeterbakken et $\mathrm{al}^{37}$ noted $84 \%$ adherence in the 10 -week intervention. Muramatsu et $\mathrm{al}^{41}$ reported half of their participants had completed 5-7 days training each week at the end of the intervention (4 months), 32\% $(n=16) 2-7$ days/week at the end, $16 \%$ "low" ("low" not described) and $2 \%$ did not do any of the exercises.

\section{Quality of the studies}

In general, the quality of the ten RCT studies was rated "medium" to "high", suggesting low risk of bias. Assessment details for potential bias in each study is presented in Table 6 . The two Burton et $\mathrm{al}^{28,29}$ studies and Saeterbakkan et al's study ${ }^{37}$ did not blind their participants, assessors or those delivering the intervention (ie, care managers) and were therefore deemed to be high risk for blinding. Allocation concealment was unclear for five of the studies and some were deemed not free of bias by the reviewers due to uneven or small sample size groups. Sequence generation and incomplete outcome data appeared to be well described and were at low risk of bias for the majority of studies.

Similar to the RCTs, the quality of the eight other studies was between ++ and + on the assessments, where it was deemed that most had satisfied the criteria for internal and external validity. It must be noted however, that all but one study did not have a comparison group, which meant a number of criteria were consequently not reported. Table 7 presents the assessment of quality for the non-RCT studies included in the review.

\section{Effectiveness of intervention programs}

Results from seven of the RCTs were included in the metaanalyses. $^{28,30,32,33,35,37,48,49}$ Two authors responded to data requests $^{30,35}$ and their data have been included in the metaanalysis, one other author responded but did not provide their data. $^{34}$ 


\begin{tabular}{|c|c|c|}
\hline+++++ & $\ddagger+$ & 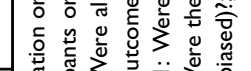 \\
\hline,+ \pm++ & ++ & $\lambda_{0}^{0}$ \\
\hline$\ddagger++++$ & $\frac{\mathscr{c}}{z} \ddagger$ & 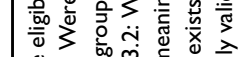 \\
\hline$\ddagger \ddagger+\ddagger \ddagger$ & $\ddagger \ddagger$ & 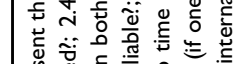 \\
\hline$\frac{\mathscr{c}}{z} \frac{\mathscr{L}}{z} \pm \frac{\mathscr{\alpha}}{z} \frac{o}{z}$ & $\frac{\mathscr{\alpha}}{z} \pm$ & $\hat{3}$ \\
\hline$\frac{o}{z} \frac{o}{z}+\frac{o}{z} \frac{o}{z}$ & $\frac{o}{z} \pm$ & $\underbrace{n}_{0}$ \\
\hline $\mathbb{z} \Sigma+\mathbb{z} \Sigma$ & $\mathbb{z} \Sigma$ & \\
\hline $\mathbb{z} \mathbb{z}+\mathbb{z} \mathbb{z}$ & 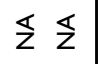 & \\
\hline$\ddagger+++\ddagger$ & $\ddagger+$ & 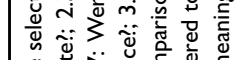 \\
\hline $\mathbb{z} \mathbb{z} \ddagger \mathbb{z} \mathbb{z}$ & $\mathbb{z} \leftleftarrows$ & \\
\hline$\ddagger \ddagger \ddagger \ddagger+$ & $\ddagger \ddagger$ & \\
\hline$\ddagger \ddagger+++$ & $\ddagger+$ & $=\subseteq$ \\
\hline$++\ddagger \ddagger \ddagger$ & \pm+ & \\
\hline$\ddagger++++$ & $+\ddagger$ & \\
\hline 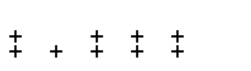 & + & \\
\hline$\ddagger \ddagger+\ddagger \ddagger$ & + & \\
\hline$\ddagger+\ddagger \ddagger \ddagger$ & $\pm \overleftarrow{z}$ & \\
\hline $\mathbb{z} \mathbb{z}+\mathbb{z} \mathbb{z}$ & $\S \leftleftarrows$ & \\
\hline 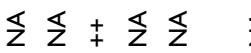 & $\S \leftleftarrows$ & \\
\hline $\mathbb{z} \mathbb{z}+\mathbb{z} \mathbb{z}$ & $\mathbb{z} \leftleftarrows$ & \\
\hline 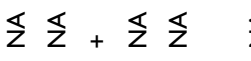 & $\S \leftleftarrows$ & \\
\hline 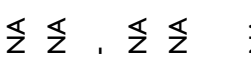 & $\S \leftleftarrows$ & \\
\hline$\ddagger \ddagger+\ddagger+$ & + & \\
\hline 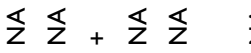 & 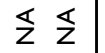 & \\
\hline$++\ddagger \ddagger+$ & ++ & \\
\hline$++\neq++$ & ++ & \\
\hline$\ddagger \ddagger \ddagger+\ddagger$ & $\ddagger+$ & \\
\hline 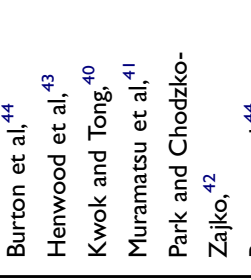 & 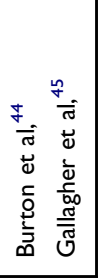 & \\
\hline
\end{tabular}

Figures 2-5 present the data in forest plots for the TUG, sitto-stand five time, grip strength, and walking speed respectively. Heterogeneity for TUG $\left(I^{2}=62 \%\right)$ and sit-to-stand five times $\left(I^{2}=65 \%\right)$ was high. The grip strength and walking speed (meters per second) analyses had no heterogeneity $\left(I^{2}=0\right)$. Sitto-stand five times was also analyzed in subgroups because there appeared to be two samples that had better function ${ }^{28,48}$ and two poorer function. ${ }^{33,37}$ The difference between those with better function and those with poorer function was significant $\left(\chi^{2}=4.05, \mathrm{df}=1(p=0.04), I^{2}=75.3 \%\right)$. However, heterogeneity was high and there was no significant improvement overall between the intervention and control groups for sit-tostand five times across the four studies. Walking speed was the only test which reported an overall significant (MD: 0.02, $p<0.001)$ difference. In this case, it favored the usual care (ie, control) group in Tinetti et al's ${ }^{49}$ study. TUG, sit-to-stand five times, and grip strength showed no statistically significant difference between the groups for these tests.

\section{Discussion}

This systematic review identified a further 18 studies, since the previous systematic review was published, ${ }^{22}$ which examined the effectiveness of physical activity/exercise interventions for older adults receiving home care services. Previously there were no studies included from Australia, however, in the last 6 years, six studies have been conducted, providing evidence for Australian home care agencies and national and state governments who fund these services. Disappointingly, we found no published studies from a number of large countries who provide home care services to older adults such as the United Kingdom, European countries (ie, the Netherlands, Ireland, Germany), and Scandinavia (other than Norway), and no studies from low to middle income countries.

Lack of consistency in methodology and measures has limited the potential to conduct meaningful meta-analyses in this area. Of the four outcomes that were analyzed by metaanalysis, only walking speed changed significantly between the intervention and control groups. On this occasion, the control group demonstrated faster walking speeds than the intervention group. This was predominantly due to Tinetti et al's ${ }^{49}$ study, which reported a faster walking speed $(\mathrm{m} / \mathrm{s})$ for the usual care group at 6 months than the intervention group. However, walking speeds were found to be the same for each group at 12 months, which was 6 months postintervention. ${ }^{49}$ Tinetti et $\mathrm{al}^{49}$ did note that the intervention group was significantly more likely to be using a walking stick than the control group at the end of the 6-month intervention. The intervention group also had more visits from 


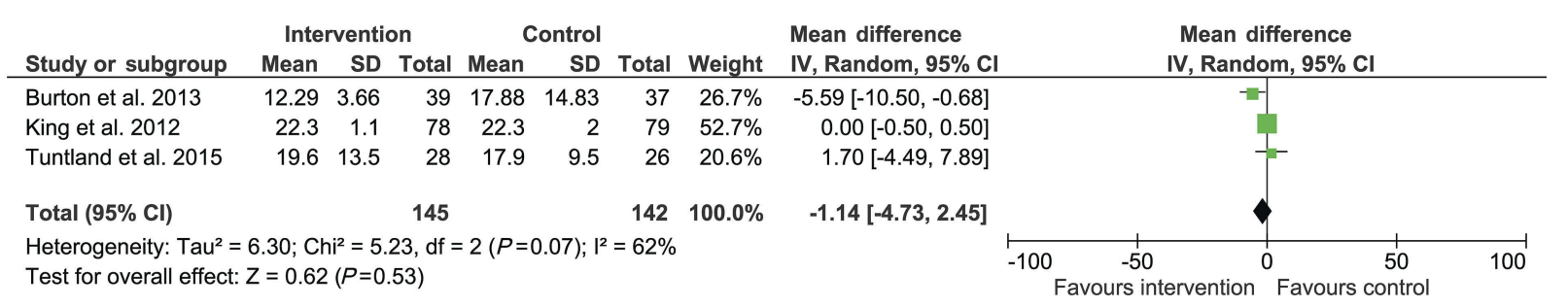

Figure 2 Timed Up and Go.

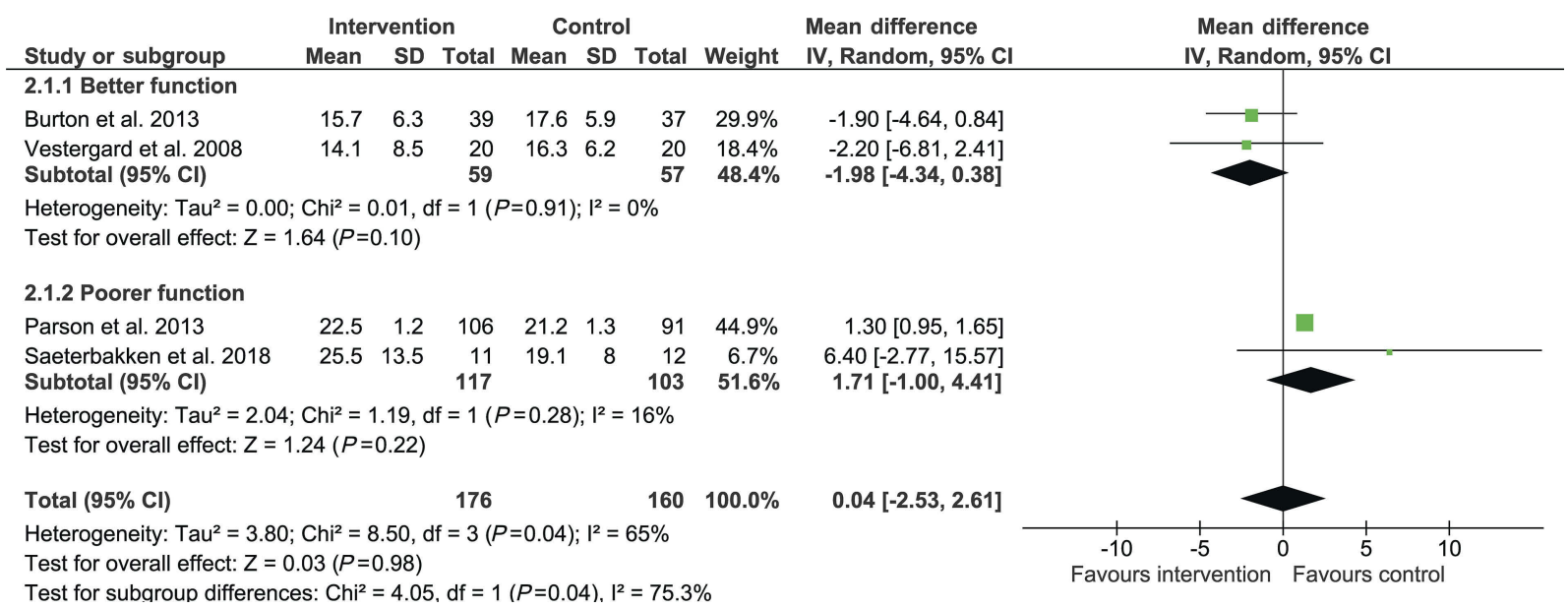

Figure 3 Sit-to-stand five times.

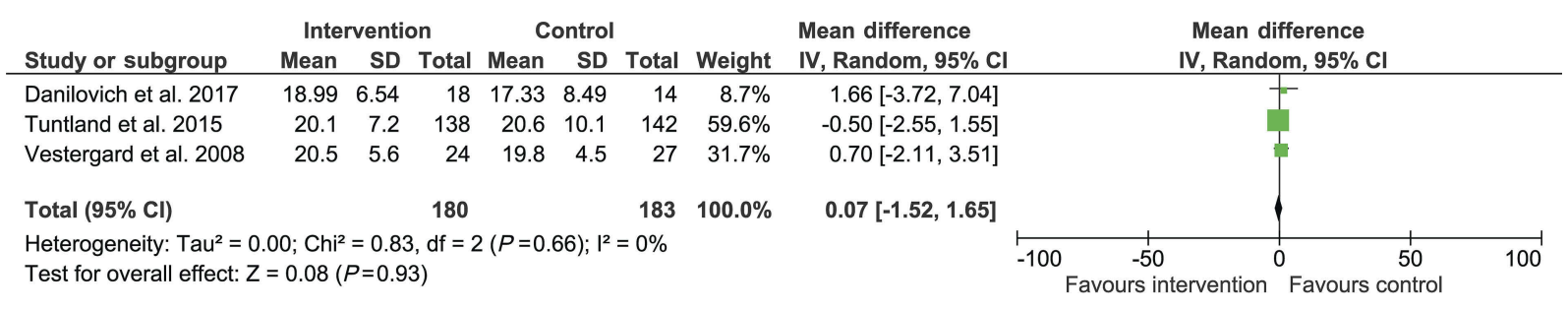

Figure 4 Grip strength.

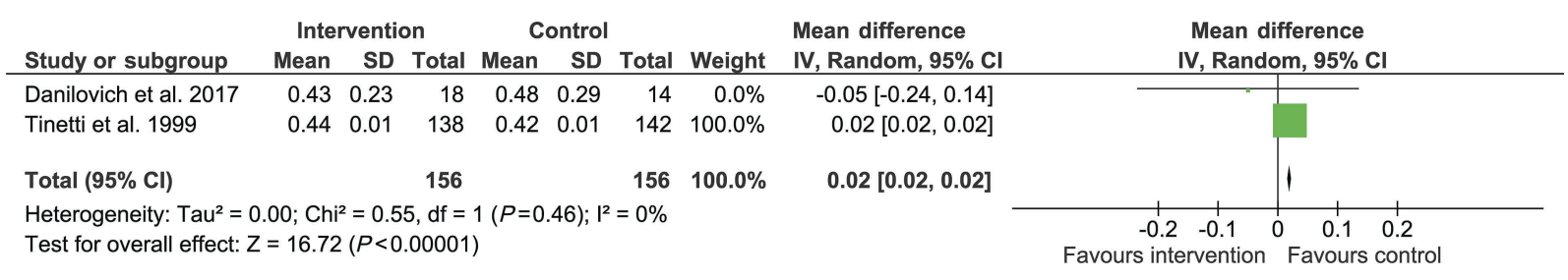

Figure 5 Walking speed.

home health aides, which perhaps meant they did not do as much physically in their daily activities. ${ }^{49}$ This may have contributed to the intervention group improving at a slower rate than the usual care group that received fewer visits from their aides and needed to do more of their own chores such as cleaning and cooking. ${ }^{49}$
The other three measures tested in the meta-analysis (TUG, sit-to-stand five times, and grip strength), showed no significant difference between the groups overall. For the TUG meta-analysis only three studies were included, two with small sample sizes (ie, under 100) and one with a total sample size of 157; heterogeneity was high and there was 
little difference between the intervention and control groups at post-testing, except for Burton et $\mathrm{al}^{28}$ whose study appeared to have greater emphasis on the exercise intervention. Similar results were found for the sit-to-stand five times test where Burton et $\mathrm{al}^{28}$ and Vestergard et $\mathrm{al}^{48}$ both reported significant improvements, compared to the other two studies, ${ }^{33,37}$ and showed a significant difference in the subgroup meta-analysis. Parson et $\mathrm{al}^{33}$ also had a considerably larger sample than the other three studies, which meant greater weighting of their results within the overall metaanalysis, similar to the TUG. This also occurred for walking speed where Tinetti et a ${ }^{49}$ reported the control group experiencing significant improvements compared to the intervention group, and their total sample size was 280 compared to Danilovich et $\mathrm{al},{ }^{30}$ with 32 participants. It must be noted however, that individual RCTs reported significant improvement and six of the eight non-RCT studies also reported significant improvements in physical function tests between pre- and post-testing. ${ }^{39-43,45}$ This gives a positive indication of an effect and indicates that additional, high quality RCTs with larger samples sizes are required to determine the true effect of the interventions.

Five of the eight RCT studies ${ }^{30,32,33,35,48}$ did not report on adherence to the exercise program section of their intervention. Previous research of older adults receiving home care services has reported this population often does not enjoy structured exercise. ${ }^{50}$ They also reported feeling too old to exercise or being in too much pain as the major reasons for not wanting to be active or exercise. ${ }^{21,50}$ The research is well established for exercise/physical activity improving function and disability, ${ }^{9,16}$ yet a vulnerable group, such as those receiving home care services, may not understand its importance and may not have participated in the exercises as often as recommended. Future research looking at physical activity/exercise with this population should report adherence in order to determine whether the intervention needs improving (ie, increased loads) or whether adherence was inadequate. It is also recommended that where possible, RCTs include a comprehensive process evaluation to improve understanding of factors influencing outcomes positively or negatively, particularly for exercise interventions.

Also of note, was that only four of the studies $37,40,42,43$ appeared to be specifically about delivering an exercise intervention. The other 14 studies included other intervention strategies as well as exercise, such as education, home safety assessments, medication reviews, and home help. Including a number of strategies within an intervention may mean the focus on exercise or physical activity is reduced and therefore the clients' functional ability, strength, balance or mobility does not improve as much as anticipated. It may therefore be more beneficial to ensure older people receiving home care services are not being recommended too many interventions at one time. Having an emphasis on selecting one or a small number of targeted interventions initially (with one of these being exercise), and doing this using a collaborative, personcentered approach with the older person may show more positive outcomes. ${ }^{51}$

The interventions were also delivered by people with a variety of levels of formal training, ranging from allied health staff (ie, physiotherapists, occupational therapists, and registered nurses) delivering the whole intervention, health professionals mentoring non-health professionals, and those without formal tertiary qualifications, such as home care workers or aides assessing and delivering participants independently. Health professionals delivering physical activity interventions has substantial cost implications compared to non-health trained professionals, which may be a reason why some studies have more recently attempted to train and utilize home care staff instead. Further RCTs are required to show whether nonallied health trained home care staff can effectively deliver physical activity interventions to improve physical function for their clients. This also raises the need for economic evaluations to be undertaken with these types of programs that have been shown to be effective, because it may also mean a reduction in the costs of home care. If this occurred it may be viewed as an investment rather than a cost to society.

\section{Strengths and limitations}

The strength of the review is that a systematic methodology was implemented to identify studies relevant to the area, that the quality of the RCTs within the review was assessed, and several meta-analyses were able to be conducted in this updated review. There are however some limitations. Although a number of large databases were searched, there is always the possibility that relevant papers may not have been included. Because the search only included peer-reviewed publications, there is always the chance that publication bias may have occurred because of unpublished and grey literature, or organizational reports being excluded. Language bias may also have resulted because only studies published in English were accepted.

\section{Conclusion}

This systematic review updated the evidence on the effectiveness of physical activity programs for older people receiving 
home care services. Although limited research is available, as evident from this review, there is absolutely none from the low middle income country context where nearly $70 \%$ of the world's old reside. Many of the studies reported significant improvements for the intervention group, particularly the single-group pre-, post-test studies. However, there is little evidence within the meta-analyses that current exercise trials are effective and none of the included studies conducted an economic evaluation, which should be considered in future studies. Greater emphasis is needed on delivering exercise as a single intervention rather than as part of a multi-factorial intervention for this population. Conducting a comprehensive process evaluation that includes adherence to the exercise intervention and how it is associated with its effectiveness is essential and recommended for future studies.

\section{Acknowledgment}

This project was funded by the Western Australian Department of Health Merit Award.

\section{Disclosure}

Dr Elissa Burton reports grants from Western Australian Department of Health Merit Award, during the conduct of the study. This grant was provided to assist with completing the paper (researcher time and paying for the open access). The authors report no other conflicts of interest in this work.

\section{References}

1. United Nations. World population prospects: the 2017 revision, key findings and advance tables. Working Paper No. ESA/P/WP/248. New York, NY: Department of Economic and Social Affairs, Population Division - United Nations; 2017.

2. Productivity Commission. Introducing Competition and Informed User Choice into Human Services: Reforms to Human Services, Draft Report. Canberra: Productivity Commission; 2017.

3. Australian Government Department of Health and Ageing. Home and Community Care Program Minimum Data Set 2009-2010 Annual Bulletin. Canberra: Australian Government Department of Health and Ageing; 2009.

4. Australian Government Department of Social Services. Home and Community Care Program Minimum Data Set 2013-14 Annual Bulletin. Canberra, ACT: Australian Government Department of Social Services. 2014.

5. Gilmour H. Health Reports: Formal Home Care Use in Canada. Ottawa, Canada: Statistics Canada; 2018.

6. Health Service Executive. National Service Plan 2018. Dublin, Ireland: Health Service Executive; 2017.

7. Cochrane A, Furlong M, McGilloway S, Molloy D, Stevenson M, Donnelly M. Time-limited home-care reablement services for maintaining and improving the functional independence of older adults. Cochrane Database Syst Rev 2016. 2016;(10). Art. No.: CD010825. doi:10.1002/14651858.CD010825.pub2
8. Kingston A, Collerton J, Davies K, Bond J, Robinson L, Jagger C. Losing the ability in activities of daily living in the oldest old: a hierarchic disability scale from the Newcastle 85+ Study. PLoSOne. 2012;7(2):e31665. doi:10.1371/journal.pone.0031665

9. Liu CJ, Latham NK. Progressive resistance strength training for improving physical function in older adults. Issue 3. Art No.: CD002759. Cochrane Database Syst Rev. 2009;(3). Art. No.: CD002759. doi:10.1002/14651858.CD002759.pub2

10. Burton E, Farrier K, Lewin G, et al. Motivators and barriers for older people participating in resistance training: a systematic review. J Aging Phys Act. 2017;25:311-324. doi:10.1123/japa.2015-0289

11. Burton E, Lewin G, Boldy D. Barriers and motivators to being physically active for older home care clients. Phys Occup Ther Geriatr. 2013;31(1):21-36. doi:10.3109/02703181.2012.751474

12. Canadian Society for Exercise Physiology. Canadian physical activity guidelines: for older adults - 65 years \& older; 2012. Availble from: http://www.csep.ca/CMFiles/Guidelines/CSEP_PAGuidelines_olderadults_en.pdf. Accessed March 26, 2013.

13. Sims J, Hill K, Hunt S, Haralambous B. Physical activity recommendations for older Australians. Australasian J Ageing. 2010;29 (2):81-87. doi:10.1111/j.1741-6612.2009.00388.x

14. U.S. Department of Health and Human Services. Physical Activity Guidelines for Americans. 2nd ed. Washington, DC: Department of Health and Human Services; 2018.

15. World Health Organisation. Global recommendations on physical activity for health 65 years and above; 2011. Available from: http:// www.who.int/dietphysicalactivity/physical-activity-recommendations -65years.pdf. Accessed July 26, 2017.

16. Liu C, Latham N. Can progressive resistance strength training reduce physical disability in older adults? A meta-analysis. Disabil Rehabil. 2011;33(2):87-97. doi:10.3109/09638288.2010.487145

17. Taylor A, Cable N, Faulkner G, Hillsdon M, Narici M, Van Der Bij A. Physical activity and older adults: a review of health benefits and the effectiveness of interventions. J Sports Sci. 2004;22 (8):703-725. doi:10.1080/02640410410001712421

18. Warburton D, Nicol C, Bredin S. Health benefits of physical activity: the evidence. Can Med Assoc J. 2006;174(6):801-809. doi:10.1503/ cmaj.051351

19. Gillespie LD, Robertson MC, Gillespie WJ, et al. Interventions for preventing falls in older people living in the community. Cochrane Database of Syst Rev. 2012;(9). Art. No.: CD007146. doi:10.1002/ 14651858.CD007146.pub3

20. Milton K, Ramirez Varela A, Strain T, Cavill N, Foster C, Mutrie N. A review of global surveillance on the muscle strengthening and balance elements of physical activity recommendations. $J$ Frailty Sarcopenia Falls. 2018;3(2):114-124. doi:10.22540/ JFSF-03-114

21. Burton E, Lewin G, Pettigrew S, et al. Identifying motivators and barriers to older community-dwelling people participating in resistance training: a cross-sectional study. J Sports Sci. 2017;35 (15):1523-1532. doi:10.1080/02640414.2016.1223334

22. Burton E, Lewin G, Boldy D. A systematic review of physical activity programs for older people receiving home care services. J Aging Phys Act. 2015;23(3):460-470. doi:10.1123/japa.2014-0086

23. Liberati A, Altman D, Tetzlaff J, et al. The PRISMA statement for reporting systematic reviews and meta-analyses of studies that evaluate health care interventions: explanation and elaboration. $B M J$. 2009;339:b2700. doi:10.1136/bmj.b2651

24. Higgins J, Altman D, Gøtzsche P, et al. The Cochrane Collaboration's tool for assessing risk of bias in randomised trials. $\mathrm{Br}$ Med $\mathrm{J}$. 2011;343:d5928. doi:10.1136/bmj.d5928

25. National Institute for Health and Care Excellence. Methods for the Development of NICE Public Health Guidance. Third ed. London: NICE; 2012. Available from: https://www.nice.org.uk/process/pmg4/ chapter/appendix-f-quality-appraisal-checklist-quantitative-intervention -studies. Accessed October 18, 2018. 
26. Higgins JPT, Green S, editors. Cochrane Handbook for Systematic Reviews of Interventions Version 5.1.0. [Updated March 2011]. The Cochrane Collaboration; 2011. Available from: www.cochranehandbook.org.

27. DerSimonian R, Laird N. Meta-analysis in clinical trials. Control Clin Trials. 1986;7(3):177-188.

28. Burton E, Lewin G, Clemson L, Boldy D. Effectiveness of a lifestyle exercise program for older people receiving a restorative home care service: a pragmatic randomized controlled trial. Clin Interv Aging. 2013;8:1591-1601. doi:10.2147/CIA.S44614

29. Burton E, Lewin G, Clemson L, Boldy D. Long term benefits of a lifestyle exercise program for older people receiving a restorative home care service: a pragmatic randomized controlled trial. Healthy Aging Clin Care Elderly. 2014;6:1-9. doi:10.4137/HACCE.S13445

30. Danilovich M, Eisenstein A, Marquez D, Corcos D, Hughes S. The impact of strong for life on the physical functioning and health of older adults receiving home and community-based services. Aging Soc. 2017;7(2):1-10. doi:10.18848/2160-1909/CGP/v07i02/1-10

31. Danilovich M, Hughes S, Corcos D, Marquez D, Eisenstein A. Translating strong for life into the community care program: lessons learned. $\mathrm{J} \mathrm{Appl}$ Gerontol. 2017;36(5):553-569. doi:10.1177/0733464815625833

32. King A, Parsons M, Robinson E, Jorgensen D. Assessing the impact of a restorative home care service in New Zealand: a cluster randomised controlled trial. Health Social Care Community. 2012;20 (4):36-374. doi:10.1111/j.1365-2524.2011.01039.x

33. Parsons J, Sheridan N, Rouse P, Robinson E, Connolly M. Randomized controlled trial to determine the effect of a model of restorative home care on physical function and social support among older people. Archives Phys Med Rehabiliation. 2013;94:1015-1022. doi:10.1016/j.apmr.2013.02.003

34. Stevens-Lapsley J, Loyd B, Falvey J, et al. Progressive multi-component home-based physical therapy for deconditioned older adults following acute hospitalization: a pilot randomized controlled trial. Clin Rehabil. 2016;30(8):776-785. doi:10.1177/0269215515603219

35. Tuntland H, Aaslund M, Espehaug B, Førland O, Kjeken I. Reablement in community-dwelling older adults: a randomised controlled trial. $B M C$ Geriatr. 2015;15:145. doi:10.1186/s12877-015-0142-9

36. Renehan E, Meyer C, Elliott R, et al. Post-hospital falls prevention intervention: a mixed-methods study. J Aging Phys Act. 2019;27 (2):155-165. doi:10.1123/japa.2017-0406

37. Saeterbakken A, Bardstu H, Brudeseth A, Andersen V. Effects of strength training on muscle properties, physical function, and physical activity among frail older people: a pilot study. J Aging Res. 2018;2018:8916274. doi:10.1155/2018/8916274

38. Bamgbade S, Dearmon V. Fall prevention for older adults receiving home healthcare. Home Healthcare Now. 2016;34(2):68-75. doi:10.1097/NHH.0000000000000333
39. Burton E, Lewin G, Clemson L, Boldy D. Determining the feasibility of a lifestyle activity program for inclusion in a restorative home care service: a pilot study. Act Adapt Aging. 2014;38(2):79-93.

40. Kwok T, Tong C. Effects on centre-based training and home-based training on physical function, quality of life and fall incidence in community dwelling older adults. Physiother Theory Pract. 2014;30 (4):243-248. doi:10.3109/09593985.2013.867387

41. Muramatsu N, Yin L, Berbaum M, et al. Promoting seniors' health with home care aides: a pilot. The Gerontologist 2018;58(4): 779788. doi:10.1093/geront/gnx101

42. Park C-H, Chodzko-Zajko W. Feasibility of integrating the "Healthy moves for aging well" program into home care aide services for frail older adults. J Exercise Rehabil. 2014;10(3):191-197. doi:10.12965/ jer. 140116

43. Henwood T, Hetherington S, Purss M, Rouse K, Morrow J, Smith M. Active@Home: investigating the value of a home care worker-led exercise program for older adults with complex care needs. J Aging Phys Act. 2019;27(2):284-289. doi:10.1123/japa.2017-0443

44. Burton E, Lewin G, O'Connell H, Petrich M, Boyle E, Hill K. Can community care workers deliver a falls prevention exercise program? A feasibility study. Clin Interv Aging. 2018;13:485-495. doi:10.2147/ CIA.S162728

45. Gallagher R, Stith N, Southard V. Evaluation of the missouri alliance for home care fall risk assessment tool and home-based "Balanced approach" fall reduction initiative. Home Health Care Manag Pract. 2013;25(5):224-228. doi:10.1177/1084822313487203

46. Clemson L, Munro J, Fiatarone Singh M. Lifestyle-Integrated Functional Exercise (Life) Program to Prevent Falls: Trainers Manual. Sydney, NSW: Sydney University Press; 2014.

47. Clemson L, Singh M, Bundy A, et al. LiFE pilot study: a randomised trial of balance and strength training embedded in daily life activity to reduce falls in older adults. Aust Occup Ther J. 2010;57:42-50. doi:10.1111/j.1440-1630.2009.00848.x

48. Verstergaard S, Kronborg C, Puggaard L. Home-based video exercise intervention for community-dwelling frail older women: a randomized controlled trial. Aging Clin Exp Res. 2008;20:479-486.

49. Tinetti M, Baker D, Gottschalk M, et al. Home-based multicomponent rehabilitation program for older persons after hip fracture: a randomized trial. Arch Phys Med Rehabil. 1999;80:916-922.

50. Burton E, Lewin G, Boldy D. Physical activity preferences of older home care clients. Int J Older People Nurs. 2014;10:170-178. doi:10.1111/opn.12065

51. Meyer C, Dow B, Hill K, Tinney J, Hill S. "The right way at the right time": insights on the uptake of falls prevention strategies from people with Dementia and their caregivers. Front Public Health. 2016;4:1-10. doi:10.3389/fpubh.2016.00001
Clinical Interventions in Aging

\section{Publish your work in this journal}

Clinical Interventions in Aging is an international, peer-reviewed journal focusing on evidence-based reports on the value or lack thereof of treatments intended to prevent or delay the onset of maladaptive correlates of aging in human beings. This journal is indexed on PubMed Central, MedLine, CAS, Scopus and the Elsevier
Bibliographic databases. The manuscript management system is completely online and includes a very quick and fair peer-review system, which is all easy to use. Visit http://www.dovepress.com/ testimonials.php to read real quotes from published authors. 